\title{
Identificação da população fúngica em amostras de ar coletadas em clínica de ensino de Odontopediatria
}

\author{
Lariane Marcolino Nunes*; Talita Silva Viana**; Gisselly Maria Campos da Silva***; Maria Paula \\ Jacobucci Botelho****; Lígia Maria Molinari Capel*****
}

* Graduada em Odontologia, Centro Universitário de Maringá

** Graduada em Ciências Biológicas, Centro Universitário de Maringá

*** Graduanda em Odontologia, Centro Universitário de Maringá

**** Professora Titular, Centro Universitário de Maringá

****** Professora Adjunta, Centro Universitário de Maringá

Recebido em 18/11/2017. Aprovado em 28/03/2018.

\begin{abstract}
RESUMO
Agentes infecciosos podem ser transmitidos via partículas microscópicas suspensas no ar e secreções presentes em superfícies contaminadas de instrumentos e equipamentos. Entre os contaminantes veiculados pelo ar em ambiente interno estão os fungos, bactérias e vírus, que são provenientes do ar externo, do sistema de climatização, da construção, mobiliário, carpete e de seus ocupantes. A maioria dos procedimentos realizados na clínica odontológica libera grande quantidade de aerossóis, partículas diminutas que ficam durante várias horas no ar e podem conter diversos micro-organismos, dentre eles, os fungos. Em clínicas de ensino, esta contaminação é maior devido ao alto número de ocupantes e de procedimentos realizados ao mesmo tempo. Ao conhecer os gêneros fúngicos aos quais seus pacientes estão expostos, o profissional pode minimizar os riscos de infecção, adotando práticas de higienização do ambiente e do ar que possam auxiliar na prevenção de doenças. A verificação de fungos foi realizada pelo método de sedimentação em placa, que se mostra útil para a análise da quantidade e da qualidade de fungos presentes em ambientes internos e externos. Foram identificadas espécies pertencentes aos gêneros Aspergillus, Fusarium, Cladosporium, Nigrospora e Penicillium, encontrados com maior frequência os gêneros Penicillium e Aspergillus provenientes de ambiente externo e interno.

Descritores: Infecções Bacterianas e Micoses. Aerossóis. Clínicas Odontológicas. Odontopediatria. Controle de infecções.
\end{abstract}




\section{INTRODUÇÃO}

Os aerossóis são definidos como partículas líquidas ou sólidas suspensas no ar, produzidas por seres humanos, animais, instrumentos ou máquinas. Os seres humanos geram bioaerossóis falando, respirando, espirrando ou tossindo. Devido à natureza de sua profissão, os profissionais de saúde estão mais expostos a micro-organismos patogênicos. O risco de exposição está em consonância com a natureza infecciosa de seus pacientes, intervenções ou instrumentos que produzem bioaerossóis ${ }^{1}$.

As Instituições de Ensino Superior (IES) têm que formar profissionais de diversas áreas com conhecimento científico adequado ao desenvolvimento de suas atividades laborais. Assim, manobras relacionadas à biossegurança de pacientes, estudantes e profissionais devem ser incorporadas à rotina clínica odontológica desde o período da graduação ${ }^{2}$. Certos profissionais, por conta de sua profissão, necessitam permanecer boa parte de seu tempo em ambientes internos como clínicas dentárias, hospitais e escritórios, que frequentemente são climatizados artificialmente. A má qualidade do ar pode levar a várias infecções respiratórias ${ }^{3}$. Sendo assim, em ambientes fechados, onde não há circulação e renovação do ar, as chances de contaminação são maiores, aumentando a propensão a diversas doenças. Dentre elas, as infecções fúngicas podem apresentar complicações graves e fatais em pacientes imunocomprometidos, com grande impacto na morbidade e mortalidade ${ }^{4}$.

Os fungos são capazes de crescer em ambientes internos onde há umidade suficiente e uma nutrição fonte, como madeira, pintura e materiais de isolamento acústico e térmico, ocorrendo a liberação de esporos como parte de seu processo reprodutivo ${ }^{5}$.

Profissionais da Odontologia devem trabalhar com máscaras cirúrgicas triplas que os protegem contra a contaminação por gotículas, mas não oferecem proteção contra aerossóis ${ }^{6}$. Assim, existe preocupação em diminuir a contaminação do ambiente odontológico, visando à proteção da equipe e dos pacientes.

A verificação de fungos pelo método de sedimentação em placa tem se mostrado útil para a análise da quantidade e da qualidade de fungos presentes em ambientes internos $\mathrm{e}$ externos. Por meio deste tipo de pesquisa tornase possível comparar os dados obtidos com contagens limítrofes estabelecidas pelo Ministério da Saúde, que traz como valor máximo aceitável para contaminação biológica $750 \mathrm{UFC} / \mathrm{m}^{3}$ de fungos. Se esse valor for ultrapassado, o ambiente é considerado impróprio para a saúde ${ }^{7}$.

A poluição do ar interior resulta da combinação de efeitos físicos, químicos e biológicos, além de outros fatores como a ventilação inadequada do ambiente. As principais fontes de poluição atmosférica externa são atividades de trânsito, industriais e de construção ${ }^{8}$. Os fungos normalmente são veiculados em um edifício pelos sistemas de aquecimento, ar condicionado e ventilação, janelas, portas e contaminantes em materiais de construção ${ }^{5}$. Assim, devem-se realizar medidas preventivas em locais propensos à contaminação do ambiente interno, que pode ser prejudicial à saúde humana.

Considerando que diversas características das clínicas-escola de Odontologia influenciam na qualidade do ar, como quantidade e fluxo de pessoas (pacientes, alunos, professores e demais funcionários); além das condições do ambiente, como circulação e umidade relativa do ar, frequência e qualidade da limpeza, os cuidados com a qualidade microbiológica do ar devem ser redobrados.

Desta forma, a análise da quantidade e da 
qualidade de fungos presentes num dado ambiente interno pode informar a necessidade ou não do melhoramento do processo de limpeza e desinfecção e, desta forma, garantir a saúde dos pacientes e dos profissionais que o frequentam. $\mathrm{O}$ presente estudo teve como objetivo quantificar e identificar os gêneros fúngicos prevalentes no ar em clínica de ensino em Odontopediatria de uma IES.

\section{MATERIAL E MÉTODOS}

As coletas de ar foram realizadas em clínica odontopediátrica de um curso de graduação em Odontologia da cidade de Maringá, com amostragens em duplicata durante um semestre letivo, sempre no turno vespertino, devido ao maior fluxo de pacientes neste período.

Para a coleta de fungos do ar foi empregado método de sedimentação em placa, pela exposição dos meios de cultura específicos para cada análise nos ambientes, isolando os micro-organismos do ar $^{9}$. Cada placa de Petri contendo $20 \mathrm{ml}$ de Ágar Sabouraud foi mantida aberta durante 20 minutos nos locais mencionados, e depois fechada. Foram anotados dados como condições climáticas nas últimas 48 horas, estação do ano, horário, dia de coleta e tipo de coleta, temperatura ambiente, umidade relativa do ar, tipo de atividades realizadas pelos ocupantes do ambiente, distância entre a placa e o solo e distância entre placa e o teto.

Foram avaliadas sete áreas distintas durante as atividades clínicas: 1 , interior da sala de raios $\mathrm{X} ; 2$, próximo à caixa de revelação portátil; 3, no corredor central que dá acesso aos boxes de atendimento; 4, ao lado de cuspideira; 5, ao lado de pia para lavagem de instrumentais; 6, ao lado do operador; e 7, ao lado da pia para lavagem das mãos. As distâncias das placas ao solo e ao teto foram padronizadas em $80 \mathrm{~cm} \mathrm{e}$ $190 \mathrm{~cm}$, respectivamente, sendo posicionadas a
$1 \mathrm{~m}$ do chão. A clínica analisada possui um condicionador de ar com vinte saídas, sem circulação ou renovação do ar e sem filtros HEPA.

As placas foram então incubadas por sete dias em estufa para fungos à temperatura de $26^{\circ} \mathrm{C}$ e umidade de $60 \%$. O crescimento dos fungos foi acompanhado diariamente. $\mathrm{O}$ número de colônias em cada placa foi contado e os dados referentes aos estudos macroscópicos (tamanho da colônia, coloração, aspecto da colônia) foram anotados. Alíquotas das colônias prevalentes foram amostradas em solução salina $0,85 \%$ estéril, com diluição das amostras em tubos contendo 9,0 $\mathrm{mL}$ de solução salina até a diluição $10^{-9}$ em placas de Agar Sabouraud. As placas foram incubadas em estufas, na temperatura de $26^{\circ} \mathrm{C}$ por cinco dias, para a obtenção de culturas puras. Passado o período de incubação, foi realizada a contagem e o isolamento das colônias com diferentes características em tubo de ensaio contendo 9,0 $\mathrm{mL}$ de Agar Sabouraud inclinado. Após a incubação, foi realizado o microcultivo dos fungos filamentosos já isolados, para a visualização das estruturas reprodutivas e vegetativas e posterior fotodocumentação.

Após o isolamento dos fungos prevalentes, amostras foram enviadas ao Instituto de Tecnologia do Paraná (Tecpar) em Curitiba para identificação.

\section{RESULTADOS E DISCUSSÃO}

As condições ambientais e a quantidade de colônias obtidas por área estão amostradas na tabela 1. As áreas 6, 2, 3 e 5 apresentaram maior índice de contaminação, seguidas das áreas 1, 7 e 4. Justifica-se o alto índice de colônias nessas áreas devido à utilização de caneta de alta rotação, jatos de ar/água e ultrassom, que aumentam a liberação de aerossóis. A contaminação ao utilizar esses equipamentos é 
de $100 \%$ em até um metro de distância, e de $50 \%$ a dois metros da boca do paciente ${ }^{10}$. A frequência de limpeza parece ser um fator importante na contaminação do ar interior. Observa-se que a frequência reduzida de limpeza do piso, das bombas à vácuo e dos condicionadores de ar aumenta a sujidade sobre estas superfícies, o que torna o ambiente contaminado e contaminante. Os métodos de desinfecção, assepsia e esterilização são essenciais nos consultórios ${ }^{11}$.

Dentre as $411 \mathrm{UFC} / \mathrm{mL}$, as 289 mais prevalentes foram selecionadas e encaminhadas para identificação. Estas são amostradas no gráfico 1. Os dados de descrição da identificação macroscópica das colônias, local da amostragem e quantidade de colônias por amostra são apresentados na tabela 2 .

Tabela 1. Condições climáticas e contagem de colônias por área avaliada

\begin{tabular}{rcccc}
\hline & Dia 1 & Dia 2 & Dia 3 & Total \\
\hline Estação do ano & Inverno & Inverno & Primavera & \\
Temperatura & $31^{\circ} \mathrm{C}$ & $26^{\circ} \mathrm{C}$ & $33^{\circ} \mathrm{C}$ & \\
Umidade relativa do ar & Sem chuva, 20\% & Nublado, 40\% & Sem chuva, 20\% & \\
Área 1 & 39 colônias & 7 colônias & 2 colônias & 48 colônias \\
Área 2 & 54 colônias & 14 colônias & 3 colônias & 71 colônias \\
Área 3 & 43 colônias & 23 colônias & 4 colônias & 70 colônias \\
Área 4 & 25 colônias & 12 colônias & 2 colônias & 39 colônias \\
Área 5 & 52 colônias & 13 colônias & 3 colônias & 68 colônias \\
Área 6 & 44 colônias & 29 colônias & 2 colônias & 75 colônias \\
Área 7 & 24 colônias & 11 colônias & 5 colônias & 40 colônias \\
Total no dia & 281 colônias & 109 colônias & 21 colônias & 411 colônias \\
\hline
\end{tabular}

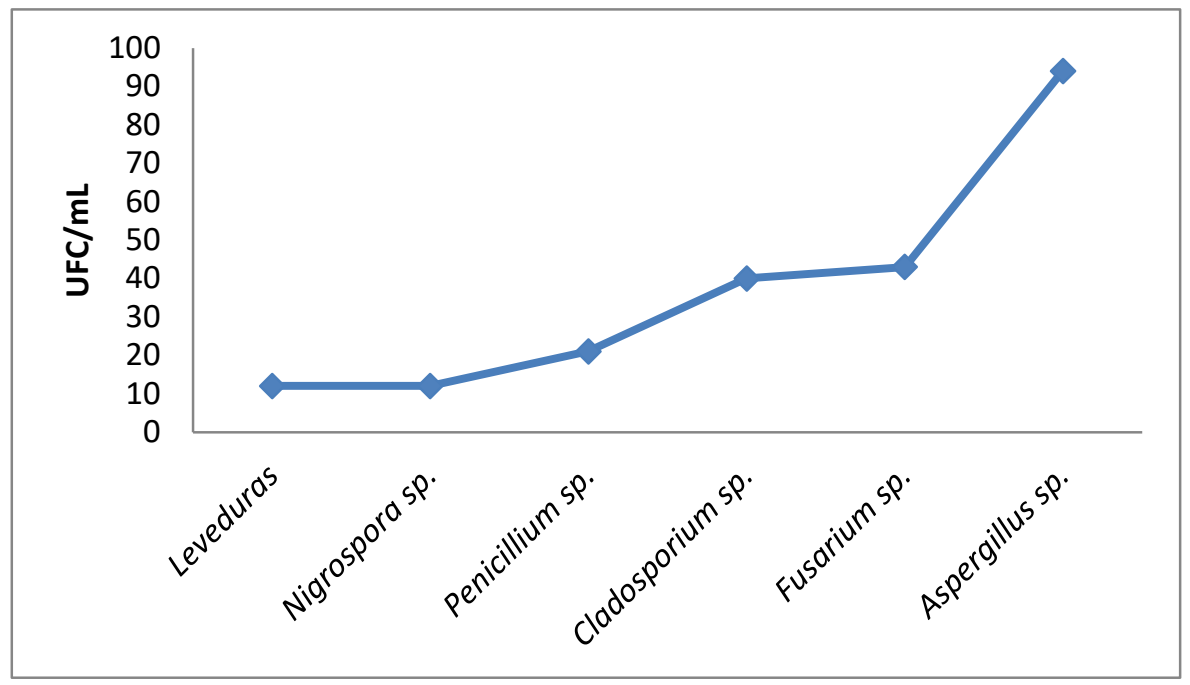

Gráfico 1. Colônias mais prevalentes identificadas no estudo 
Tabela 2. Identificação macroscópica das colônias, local da amostragem e quantidade de colônias por amostra

\begin{tabular}{|c|c|c|c|c|}
\hline Amostra & Descrição Macroscópica & Área & $\mathbf{N}^{\circ}$ & Resultado Micromorfológico \\
\hline 01 & $\begin{array}{c}\text { Aspecto cotonoso, com bordas claras, regulares e esbranquiçadas, coloração } \\
\text { verde escuro }\end{array}$ & $1,2,4,5$ & 18 & $\begin{array}{l}\text { Fungo filamentoso não identificado com } \\
\text { material de contaminação }\end{array}$ \\
\hline 02 & Aspecto cotonoso, com bordas irregulares, esbranquiçadas, com núcleo róseo & $1,3,7$ & 12 & Nigrospora $\mathrm{sp}$ \\
\hline 03 & $\begin{array}{l}\text { Aspecto cotonoso, com bordas claras, regulares e definidas, coloração marrom } \\
\text { claro, com núcleo verde claro e um ponto branco no centro }\end{array}$ & $1,3,4,7$ & 13 & Aspergillus sp \\
\hline 04 & $\begin{array}{c}\text { Aspecto cotonoso, com bordas claras e bem definidas, regulares, coloração verde } \\
\text { escuro e com centro verde escuro intenso }\end{array}$ & $\begin{array}{c}2,3,4,6 \\
7\end{array}$ & 28 & Aspergillus sp \\
\hline 05 & $\begin{array}{c}\text { Aspecto cotonoso, com bordas claras e bem definidas, regulares, coloração verde } \\
\text { escuro e com centro verde escuro }\end{array}$ & $\begin{array}{l}2,3,4,6 \\
7\end{array}$ & 30 & Aspergillus sp \\
\hline 06 & $\begin{array}{l}\text { Aspecto cotonoso, com bordas claras, regulares e definidas, coloração branco } \\
\text { com núcleo marrom }\end{array}$ & $\begin{array}{c}1,2,3,5 \\
7\end{array}$ & 11 & Penicillium sp \\
\hline 07 & $\begin{array}{l}\text { Aspecto cotonoso, com bordas verde claro e branco, regulares e definidas, e } \\
\text { coloração verde escuro }\end{array}$ & $\begin{array}{l}1,2,3,4 \\
5,6,7\end{array}$ & 23 & Aspergillus sp \\
\hline 08 & Aspecto cotonoso, com bordas claras e definidas, coloração rosa salmão & $1,2,6,7$ & 25 & Fusarium sp \\
\hline 09 & Aspecto leitoso, bem definido, coloração rósea & $2,4,6,7$ & 12 & $\begin{array}{l}\text { Micro-organismo com características de Bacilo } \\
\text { Gram+ }\end{array}$ \\
\hline 10 & $\begin{array}{l}\text { Aspecto cotonoso, com bordas claras, regulares e esbranquiçadas, coloração } \\
\text { verde claro }\end{array}$ & $\begin{array}{c}1,3,5,6 \\
7\end{array}$ & 10 & Penicillium $\mathrm{sp}$ \\
\hline 11 & $\begin{array}{c}\text { Aspecto cotonoso, com bordas claras, regulares e bem definidas, e coloração } \\
\text { verde com núcleo mais escuro }\end{array}$ & $1,2,4,6,7$ & 21 & Cladosporium sp \\
\hline 12 & Aspecto cotonoso, com bordas claras e definidas, coloração rosa salmão & $1,2,6,7$ & 18 & Fusarium $\mathrm{sp}$ \\
\hline 13 & $\begin{array}{c}\text { Aspecto leitoso, com bordas definidas e opacas, coloração branco, com pequeno } \\
\text { núcleo bege }\end{array}$ & $\begin{array}{l}1,2,3,4 \\
5,6\end{array}$ & 22 & $\begin{array}{l}\text { Micro-organismo com características de } \\
\text { bactéria (Bacilo Gram positivo) }\end{array}$ \\
\hline 14 & $\begin{array}{l}\text { Aspecto cotonoso, com bordas claras, regulares e bem definidas, coloração verde } \\
\text { com núcleo mais escuro }\end{array}$ & $2,3,6,7$ & 19 & Cladosporium $\mathrm{sp}$ \\
\hline 15 & $\begin{array}{c}\text { Aspecto cotonoso, com bordas brancas regulares e bem definidas, coloração } \\
\text { verde claro. }\end{array}$ & $1,3,4,6$ & 15 & $\begin{array}{l}\text { Fungo filamentoso septado dematiáceo não } \\
\text { identificado }\end{array}$ \\
\hline 16 & Aspecto verrucoso, com bordas definidas e irregulares, coloração bege. & $2,3,4,5$ & 12 & $\begin{array}{l}\text { Micro-organismo com característica de } \\
\text { leveduras }\end{array}$ \\
\hline
\end{tabular}


Em amostras de ar coletadas ao ar livre, espécies pertencentes aos gêneros Aspergillus, Penicillium e Cladosporium são comuns. Esses gêneros também são predominantes em ambientes internos indicando uma forte correlação na presença de fungos entre ar interior e exterior ${ }^{12}$.

De acordo com a Resolução RE n ${ }^{\circ}$ 570, de 3 de outubro de 2002, da Agência Nacional de Vigilância Sanitária (ANVISA), é inaceitável a presença de fungos patogênicos e toxigênicos em ambientes internos climatizados artificialmente, de uso público e coletivo. Já em relação à quantidade de fungos não patogênicos $\mathrm{e}$ toxigênicos, o limite permitido é $750 \mathrm{UFC} / \mathrm{m}^{3}$ de fungos ${ }^{7}$.

Em estudo realizado previamente também em clínica odontopediátrica, os gêneros Aspergillus e Penicillium foram encontrados em maior número de colônias no ambiente interno. Embora os gêneros mais comuns tenham sido saprófitas, incluindo aqueles que vivem em material vegetal em decomposição, Cladosporium, Alternaria, Epicoccum e Aureobasidium, as espécies baseadas no solo, como Aspergillus e Penicillium, foram relativamente baixas em número no ar exterior, mas foram encontrados em níveis aumentados em ambientes fechados ${ }^{5}$.

Entre as 16 amostras enviadas para identificação, 4 pertenciam ao gênero Aspergillus. A maioria desses gêneros de fungos é conhecida por serem patógenos oportunistas que podem levar a doenças pulmonares crônicas ou doenças alérgicas nos hospedeiros ${ }^{3}$. Em indivíduos saudáveis, os conídios de Aspergillus são eficientemente eliminados por macrófagos e neutrófilos. No entanto, quando o hospedeiro é imunocomprometido, como a neutropenia induzida por quimioterapia ou através do uso crônico de corticosteroides, a inalação de conídios de Aspergillus (esporos) pode causar um espectro de doenças como a aspergilose invasiva e aspergilose pulmonar necrotizante crônica ${ }^{13}$.
Desta forma, em ambiente clínico onde se presta atendimento a crianças, o controle da qualidade do ar é essencial para a prevenção de doenças.

Esporos de Aspergillus, Penicillium e Cladosporium são prevalentes em ambientes aquáticos e atmosféricos. Especialmente algumas das espécies de Aspergillus como A. fumigatus e A. versicolor têm toxigênicos e características infecciosas ${ }^{3}$.

Os gêneros Aspergillus, Penicillium $e$ Cladosporium têm envolvimento potencial nas Síndromes do Edifício Doente $(\mathrm{SED})^{12}$. A presença dos gêneros Aspergillus e Penicillium já era esperada já que são comuns em ambientes externos e internos ${ }^{15}$.

As manifestações clínicas relacionadas às espécies de Penicillium incluem infecções superficiais e invasivas, bem como alergias. As infecções nos humanos estão principalmente relacionadas à imunidade do hospedeiro, podendo apresentar alterações mais graves em indivíduos imunocomprometido, favorecendo processos infecciosos ${ }^{16}$.

O gênero Cladosporium é comumente encontrado na natureza, porém possui capacidade de crescimento em superfície de ambientes internos com baixos níveis de umidade, principalmente os com climatização artificial ${ }^{15}$. As espécies de Cladosporium não são relatadas como produtoras de micotoxinas, mas não deixam de representar uma ameaça para a saúde ${ }^{12}$, pois estão associadas a lesões cutâneas, ungueais e cerebrais ${ }^{17}$. O gênero Fusarium também é um agente causador de infecções respiratórias graves em pessoas imunocomprometidas ${ }^{18}$.

Em uma clínica odontológica, a maior fonte de contaminação é a boca do paciente ${ }^{10}$ e a principal atividade do $\mathrm{CD}$ consiste em remover tecido contaminado envolto de fluidos corporais sangue e saliva ${ }^{11}$. Sabendo disso, medidas para evitar a contaminação cruzada no ambiente odontológico são essenciais. Esta contaminação ocorre por meio do ar, objetos ou de pessoa para 
pessoa, e para preveni-la são necessários rigorosos cuidados de biossegurança ${ }^{10}$.

Para a solução de efeitos desfavoráveis dos fungos em saúde pública, pesquisas adicionais sobre ambientes internos são necessárias ${ }^{3}$. Pode ocorrer variação sazonal em relação à área colonizada com diferentes gêneros fúngicos de Penicillium e Cladosporium a partir da primavera para o verão, podendo ocorrer uma diminuição de Penicillium e aumento de Cladosporium. Assim é esperado que os gêneros fúngicos apresentem-se em diferentes concentrações nas estações do ano, havendo predominância de acordo com o gênero e o ambiente, o que justifica as diferentes quantidades de colônias relatada no estudo ${ }^{19}$.

Tanto a temperatura como a disponibilidade de água afetam as características de crescimento e esporulação dos fungos aéreos, com temperatura ambiente mais alta e água disponível, favorecendo um crescimento mais rápido. A liberação de esporos é posteriormente aumentada por períodos intermitentes de secura onde os esporos são dispersos e a umidade permitindo um maior crescimento e esporulação. As espécies de fungos encontradas habitualmente refletem aquele ambiente ao ar livre, embora as concentrações possam mudar sazonalmente ou localmente, onde o interior o ambiente é favorável ao crescimento de espécies específicas ${ }^{4}$. Esta condição remete aos resultados relatados no estudo, o qual o ambiente interno da clínica odontopediátrica apresenta condições habituais para propagação fúngica no ambiente, uma vez que diferentes gêneros fúngicos foram identificados, havendo prevalência do gênero Aspergillus e Penicilluim.

O ambiente odontológico estudado apresentou-se como de alto risco para contaminação fúngica. Assim, é necessário que se faça o controle do ar do ambiente da clínica de forma contínua, para que se possa monitorar a influência das estações climáticas, bem como dos processos de limpeza e desinfecção utilizados no ambiente.
Para que se possa garantir biossegurança adequada, é preciso recursos humanos adequadamente esclarecidos e treinados em ações que sejam capazes de promover mudanças nos serviços de saúde, além das instituições de ensino e pesquisa para prevenir, diminuir ou eliminar os riscos inerentes às profissões da saúde ${ }^{20}$. Desta forma será possível implementar medidas preventivas adequadas, pois é inaceitável a presença de fungos patógenos e toxigênicos no ambiente de saúde.

A utilização de filtros tipo HEPA poderá auxiliar na retenção de impurezas, diminuindo contaminantes via aerossóis presentes no ambiente. No entanto, sua utilização ainda não é rotina. Este estudo pode auxiliar na conscientização dos profissionais a respeito de sua utilização. Assim como ser deve ser realizada orientação aos profissionais da limpeza no que se refere à frequência na limpeza e manutenção dos aparelhos/ equipamentos, e aos profissionais da Odontologia quanto ao correto uso dos equipamentos de proteção individual.

Ao realizar pequenas ou grandes cirurgias, o $\mathrm{CD}$ deve estar atento à contaminação proveniente do ar, pois esta também é importante para que o período pós-cirúrgico seja bem-sucedido e sem intercorrências para o paciente. Ao conhecer os gêneros fúngicos aos quais seus pacientes estão expostos, o $\mathrm{CD}$ pode minimizar os riscos de infecção pelo ar, adotando práticas de limpeza do ambiente e do ar que possam auxiliar na prevenção contra doenças fúngicas pósoperatórias.

\section{CONCLUSÃO}

Neste estudo evidenciou-se que o gênero fúngico mais prevalente foi o Aspergillus que pode, nesta população, representar um risco significativo para a problemas pulmonares e desencadear processos alérgicos em populações mais vulneráveis. Os outros gêneros encontrados em ordem decrescente foram Fusarium, 
Cladosporium, Penicillium e Nigrospora, todos reconhecidos como agentes de possíveis infecções oportunistas para pacientes com imunidade reduzida. O presente estudo contribui ainda para avaliação da qualidade do ar, no entanto, é evidente a necessidade de estudos randomizados controlados para auxiliar a tomada de decisão de medidas para a prática clínica.

\section{ABSTRACT \\ Identification of the fungal population in air samples collected at Pediatric Dentistry teaching clinic}

Infectious agents can be transmitted via microscopic particles suspended in the air and secretions present on contaminated surfaces of instruments and equipment. Indoor airborne contaminants include fungi, bacteria and viruses, which come from outside air, the air conditioning system, the building, furniture, carpet and their occupants. Most procedures performed at the dental clinic release large amounts of aerosols, minute particles that remain for several hours in the air and may contain several microorganisms, among them fungi. In teaching clinics, this contamination is greater due to the high number of occupants and procedures performed at the same time. By knowing the fungal genera to which their patients are exposed, the professional can minimize the risks of infection, adopting practices of hygiene of the environment and air that can aid in the prevention of diseases. The fungi check was performed by the plate sedimentation method, which is useful for the analysis of the quantity and quality of fungi present in internal and external environments. Species belonging to the genus Aspergillus, Fusarium, Cladosporium, Nigrospora and Penicillium were identified, most frequently found Penicillium and Aspergillus genera from external and internal environment.

Descriptors: Bacterial Infections and Mycoses. Aerosols. Dental Clinics. Pediatric Dentistry. Infection Control.

\section{REFERÊNCIAS}

1. Zemouri C, de Soet H, Crielaard W, Laheij A. A scoping review on bio-aerosols in healthcare and the dental environment. Plos One. 2017;12(5):e0178007. DOI: 10.1371/ journal.pone.0178007.

2. Brasil. Lei de Diretrizes e Bases da Educação Nacional. Lei $n^{0}$ 9.394/1996 Lei $\mathrm{n}^{0} \quad 4.024 / 1961$ artigo 43. Senado Federal. Brasília: Coordenação de Edições Técnicas; 2017.

3. Kadaifciler D, Cotuk A. Microbial contamination of dental unit waterlines and effect on quality of indoor air. Environ Monit Assess. 2014; 186(6):3431-44.

4. Boch T, Reinwald M, Postina P, Cornely O, Vehreschild J, Spiess B, et al. Identification of invasive fungal diseases in immunocompromised patients by combining an Aspergillus specific PCR with a multifungal DNA-microarray from primary clinical samples. Mycoses. 2015; 58(12):735-45.

5. Rogawansamy $\mathrm{S}$, Gaskin $\mathrm{S}$, Taylor $\mathrm{M}$, Pisaniello D. An evaluation of antifungal agents for the treatment of fungal contamination in indoor air environments. Int J Environ Res Public Health. 2015; 12(6):6319-32.

6. Brasil. Cartilha de proteção respiratória contra agentes biológicos para profissionais da saúde. Brasília: Ministério da Saúde, 2009.

7. Brasil. Ministério da Saúde. Agência Nacional de Vigilância Sanitária. Resolução $\mathrm{n}^{\circ}$ 9, de 16 de janeiro de 2003. Orientação técnica sobre padrões referenciais de qualidade do ar interior em ambientes climatizados artificialmente de uso público e coletivo. Diário Oficial da União, Brasília, DF, 20 jan. 2003.

8. Barreto ACB, Vasconcelos CPP, Girao CMS, Rocha MMNP, Mota OML, Pereira SLS. Contaminação do ambiente odontológico por aerossóis durante atendimento clínico com uso de ultrassom. 
Braz J Periodontol. 2011; 21: 79-84.

9. Jurado S, Bankoff A, Sanchez A. Indoor air quality in Brazilian universities. Int $\mathbf{J}$ Environ Res Public Health. 2014; 11(7): 7081-93.

10. Sousa KS, Fortuna JL. Microrganismos em ambientes climatizados de consultórios odontológicos em uma cidade do extremo sul da Bahia. Rev Baiana Saúde Pública. 2011; 35(2): 250-63.

11. Segers F, Meijer M, Houbraken J, Samson R, Wösten H, Dijksterhuis J. Xerotolerant Cladosporium sphaerospermum are predominant on indoor surfaces compared to other Cladosporium Species. Plos One. 2015; 10(12):e0145415. DOI: 10.1371/ journal.pone.0145415.

12. Kolwijck E, van de Veerdonk F. The potential impact of the pulmonary microbiome on immunopathogenesis of Aspergillus-related lung disease. Eur J Immunol. 2014; 44(11): 3156-65.

13. Hayleeyesus SF, Manaye AM. Microbiological quality of indoor air in university libraries. Asian Pac J Trop Biomed. 2014; 4(1):321-17.

14. de Sant'anna JB, Santos CF, Carneiro JA, Coutinho FN. Investigação de fungos anemófilos em ambiente cirúrgico do Hospital Regional de Brazlândia-DF. Proceedings COPEC. 2010; 7(10): 409-12.
15. Guevara-Suarez M, Sutton D, Cano-Lira J, García D, Martin-Vicente A, Gené J, et al. Identification and antifungal susceptibility of Penicillium-like fungi from clinical samples in the United States. J Clin Microbol. 2016; 54(8): 2155-61.

16. Melo LLS, Lima AMC, Damasceno CAV, Vieira ALP. Flora fúngica no ambiente da Unidade de Terapia Intensiva Pediátrica e Neonatal em hospital terciário. Rev Paul Pediatr. 2009; 27(3):303-8.

17. Haleem Khan AA, Mohan Karuppayil S. Fungal pollution of indoor environments and its management. Saudi J Biol Sci. 2012; 19(4):405-26.

18. Frankel M, Hansen E, Madsen A. Effect of relative humidity on the aerosolization and total inflammatory potential of fungal particles from dust-inoculated gypsum boards. Indoor Air. 2014;24(1):16-28.

19. Neder RN. Microbiologia: manual de laboratório. São Paulo, Brasil: Editora Nobel; 1992.

20. Ministério da Saúde (BR). Biossegurança em saúde: prioridades e estratégias de ação. Brasília: Ministério da Saúde; 2010.

Correspondência para:

Lígia Maria Molinari Capel

e-mail: ligia.capel@ unicesumar.edu.br

UniCesumar

Av. Guedner, 1610 Jardim Aclimação

87050-390 Maringá/PR. 